\title{
GÊNEROS E SEXUALIDADES NA FORMAÇÃO DE DOCENTE: ANALISANDO SABERES A PARTIR DE OFICINAS PEDAGÓGICAS
}

\author{
Marcelo Gustavo Andrade de SOUZA ${ }^{\mathbf{1}}$ \\ Pontifícia Universidade Católica do Rio de Janeiro-PUC/RJ \\ Marcelo-andrade@puc-rio.br \\ Rachel Luiza Pulcino de ABREU 2 \\ Pontifícia Universidade Católica do Rio de Janeiro-PUC/RJ \\ rachelpulcino@gmail.com \\ Raquel Alexandre Pinho dos SANTOS 3 \\ Pontifícia Universidade Católica do Rio de Janeiro-PUC/RJ \\ raquel.aps@gmail.com \\ Felipe BASTOS 4 \\ Pontifícia Universidade Católica do Rio de Janeiro-PUC/RJ \\ bastos.fe@gmai.com
}

\begin{abstract}
Resumo: $O$ que pensam as estudantes de Pedagogia e Licenciaturas sobre os gêneros $e$ as sexualidades? Quais são suas principais dúvidas sobre esses temas? Quais são as possibilidades de debater a diversidade de gênero e as sexualidades na formação docente? Nesse artigo, analisamos as experiências da aplicação da oficina "Corpo, gênero e sexualidade na escola", realizada em três turmas, de duas universidades cariocas. Para isso, trazemos reflexões de materiais produzidos pelas alunas. Assim, pretendemos lançar algumas pistas sobre a construção de saberes em gêneros e sexualidades na formação docente.
\end{abstract}

Palavras chave: Gênero. Sexualidade. Formação docente. Oficinas pedagógicas.

\begin{abstract}
What do Pedagogy students and Pre-service teachers think about gender and sexuality? What are their main doubts about these issues? What are the possibilities of discussing gender diversity and sexualities in the pre-service teacher education? In this paper, we analyze the experiences associated with the implementation of the workshop "Body, gender, and sexuality in the school", performed in three classes from two different universities in Rio de Janeiro. For that purpose, we bring some of the reflections found in the materials produced by these students during this workshop. By doing so, we aim to give some hints about knowledge construction on gender and sexualities in the pre-service teacher education.
\end{abstract}

Keywords: Gender. Sexuality. Pre-service Teacher Education. Pedagogical workshops.

\footnotetext{
${ }^{1}$ Licenciado em Filosofia (1995); Sociologia (1996) e História (1996); Mestre em Educação (2000) e Doutor em Ciências Humanas / Educação (2006) pela Pontifícia Universidade Católica do Rio de Janeiro (PUC-Rio). Realizou o Programa de Doutorado no Exterior - PDSE/CNPq (2005) na Universitat de València, Espanha. Professor Associado do Departamento de Educação PUC/RIO.

${ }^{2}$ Bacharela e Licenciada em História pela UGF. Mestra em Educação pela PUC-Rio. Atualmente cursa o doutorado em Educação na PUC-Rio.

3 Mestrado em Educação pela Pontifícia Universidade Católica do Rio de Janeiro, Brasil(2011). Pesquisadora Associada da Pontifícia Universidade Católica do Rio de Janeiro , Brasil

${ }^{4}$ Doutorado em andamento em Educação pela PUC do Rio de Janeiro, PUC-Rio. Mestrado em Educação pela mesma universidade.
} 


\section{Introdução}

Por que a educação deve discutir gênero e sexualidade? Como trabalhar a diversidade de gênero na escola? Gênero é uma construção social/cultural ou tem relação também com a constituição biológica que difere homens e mulheres?

Essas questões, produzidas pelas ${ }^{5}$ estudantes durante as oficinas pedagógicas, levantam dúvidas relacionadas à prática docente, especificamente ao trabalho com relações de gênero e sexualidades em sala de aula. Elas nos dizem sobre uma necessidade de compreender porque esses temas surgem com força e qual seria a sua importância para o processo educacional. Com isso, também evidenciam a dificuldade dos debates sobre gênero e sexualidade em se propagarem nos espaços de ensino, o que gera desconhecimento de significados e de histórias.

Quando aos conceitos mobilizados nessa análise de experiência, partimos da reflexão de Joan $\operatorname{Scott}^{6}$ (1995), ao afirmar que as relações de gênero são constitutivas dos sujeitos e, como tal, estão imersas em relações de poder. Quanto às sexualidades, compreendemos que elas englobam múltiplas influências: sociais, culturais, psicológicas e biológicas. Sendo assim, falar em identidades de gênero e sexualidades é compreender que essas duas categorias estão num processo de constituição constante, compondo todas as experiências dos sujeitos.

Destacamos também a categoria saber. Saber, conhecimento, experiência, prática, habilidade. O saber tem sido analisado e classificado por diferentes autoras no esforço de compreensão dessa categoria. Alice Lopes (1999) destaca o fato de que o conhecimento escolar não é somente constituído pelos saberes científicos formalizados em conjunto dos saberes cotidianos vividos, mas transformado, principalmente, da organização destes últimos. Da mesma forma, o saber presente nas salas de aula do ensino superior emerge da tensão entre os conhecimentos formalizados e os conhecimentos vividos, preenchido

\footnotetext{
${ }^{5} \mathrm{~A}$ regra gramatical da língua portuguesa que define o masculino como elemento neutro em substantivos e adjetivos foi deliberadamente invertida para o feminino, independentemente do sexo dos sujeitos ao qual o termo se refere. Seguindo esta lógica, os substantivos e adjetivos usados no masculino neste texto ocorrem somente em referência específicas a sujeitos masculinos (Felipe BASTOS, 2015). "É, pra mim, estranho que pessoas sofisticadas em questões de poder, política e linguagem continuem isentando a gramática de qualquer cumplicidade na perpetuação de relações de desigualdade. (...) Apesar da dificuldade de lidar com essa questão em uma língua extremamente flexionada como o Português, continuo achando que vale a pena tentar encontrar soluções (N. do T.)" (Elizabeth ELLSWORTH, 2001, p. 75).
}

${ }^{6}$ Referenciar autoras com nome e sobrenome e não apenas sobrenome como feito usualmente é uma forma de evidenciar os gêneros e, por consequência, as mulheres na pesquisa, o que contribui com as lutas de reconhecimento e com valorização da identidade feminina de forma mais ampla (Raquel PINHO; Rachel PULCINO, 2016). 
no intercâmbio das interações. Jean Forquin (1993) aponta que tais saberes se configuram a partir de uma seleção do que se constituiu como verdade pautada por disputas de poder. Assim, ensinar é colocar alguém em presença de certos elementos da cultura, ou seja, é uma atividade seletiva e normativa da cultura. Pensar nos saberes mobilizados pelas alunas para abordar os temas pretendidos é por em destaque estas disputas, seleções e normatividades.

Sobre a concepção de oficina pedagógica, delinearemos a seguir.

\section{As oficinas pedagógicas}

O presente texto busca debruçar-se sobre três oficinas pedagógicas, realizadas em 2016, em duas universidades do Rio de Janeiro: duas ocorreram na Pontifícia Universidade Católica do Rio de Janeiro (PUC-Rio) e uma na Universidade Federal do Rio de Janeiro (UFRJ). Na PUC-Rio, uma oficina foi realizada em uma disciplina de Fundamentos da Educação (Turma A) e outra em uma disciplina recém-incorporada ao quadro de obrigatórias (Turma B), mas que já existia na instituição como eletiva, destinada a abordar temas como cultura, diferença e identidade. Na UFRJ, a oficina foi realizada também em uma disciplina de Fundamentos da Educação (Turma C). As oficinas tiveram duração de duas horas.

Oficina é o lugar onde se constrói, fabrica e se elabora alguma coisa, é também um local onde se trabalha e se aprende. Segundo Cubelles Gonzales (1987), oficina é o lugar do exercício de um ofício, uma ocupação manual e que, desta forma, supõe certo grau de habilidade e aptidão. Em tal atividade, teoria e prática não são excludentes. Assim, é onde se faz, espaço onde se constrói. Por isso, Marcelo Andrade e Maria Lucinda (2011, p. 258, grifos dos autores) indicam que "um aprendiz numa oficina de trabalho, como indica o termo que lhe confere função, não apenas trabalha, ele, 'aprende trabalhando"". Tal como as oficinas que se propõem a ser espaço de construção e aprendizados, entendemos que a prática de uma oficina pedagógica compreende o conhecimento como algo a ser construído, num processo tanto pessoal, pois parte das experiências prévias das participantes, quanto coletivo, pois valoriza o exercício dialógico democrático.

Marcelo Andrade e Suzana Sacavino (2011) destacam que o trabalho com oficinas pedagógicas possui duas características essenciais: trabalho coletivo e processo de ensino-aprendizagem relacionando teoria e prática. Para as autoras, a oficina é um lugar 
onde não se perde a noção do todo, diferente da fábrica que é marcada pela divisão das funções. Além disso, as oficinas "são mais que uma mera estratégia técnicometodológica; são uma aposta nos processos de ensino-aprendizagem que ajudam a trazer à tona uma concepção de educação que congrega de maneira adequada a perspectiva dos direitos humanos" (Idem, p. 265). É a partir desta perspectiva dialógica e participativa que trabalhamos.

As oficinas pedagógicas podem ser marcadas em três momentos (Marcelo ANDRADE; Maria LUCINDA, 2011): sensibilização, aprofundamento e compromisso. Cada uma dessas etapas possui um objetivo específico a ser alcançado e estão articuladas entre si, para que ao final da oficina o grupo perceba o caminho percorrido coletivamente na construção dos saberes. Em cada momento será exigido um tipo de habilidade diferente e conta com materiais e métodos diversificados.

A sensibilização aproxima o sujeito da realidade e reconhece o conhecimento já existente do sujeito, envolvendo-o na atividade. O aprofundamento é a reflexão a partir de um material de apoio, geralmente um texto. Nessa etapa, pretendemos avançar no conhecimento. Ao fim do aprofundamento, é realizada uma síntese, que organiza ideias e sentimentos, geralmente construídos coletivamente e elabora consensos. O compromisso é uma atividade lúdica, que geralmente resulta em um produto, com o objetivo de reforçar a ideia principal da oficina, de modo que o público-alvo saia motivado a estudar e conhecer mais sobre o assunto.

Deste modo, os momentos das oficinas sobre relações de gênero e sexualidades consistiam em: (i) a prática da caixa de perguntas, (ii) leitura e discussão de conceitos de gênero e sexualidade, e (iii) a proposta de uma reflexão pessoal a partir do vídeo Não é pra sair, de Nátaly Neri e Jout jout ${ }^{7}$ (Apêndice 1). Neste trabalho, nos deteremos na análise da primeira atividade, a caixa de perguntas.

\section{As caixas de perguntas}

Os Parâmetros Curriculares Nacionais (PCN - BRASIL, 1998, p. 333) já sugeriam a técnica da caixa de perguntas como uma alternativa para o debate de orientação sexual na escola. Ao longo dos anos, vários foram apresentados e publicados trabalhos relatando

\footnotetext{
${ }^{7}$ Disponível em: <https://www.youtube.com/watch?v=uTrLpclk3j4>. Acesso em: 02 set. 2016 MARGENS - Revista Interdisciplinar Dossiê: Corpo, Gênero e Sexualidade Versão Digital - ISSN: 1982-5374 VOL.11. N. 17. Dez 2017. (p. 59-75)
} 
e analisando a experiência com esta técnica na educação básica (Larissa VENÂNCIO et al, 2016; Carla de MORAES et al, 2005).

Costumo dizer que toda pergunta formulada já traz consigo uma gama de informações e pré-concepções a respeito do assunto e, partindo dela, pode-se avançar, mais eficientemente, no trabalho pedagógico. (Jimena FURLANI, 2009, p. 177-178)

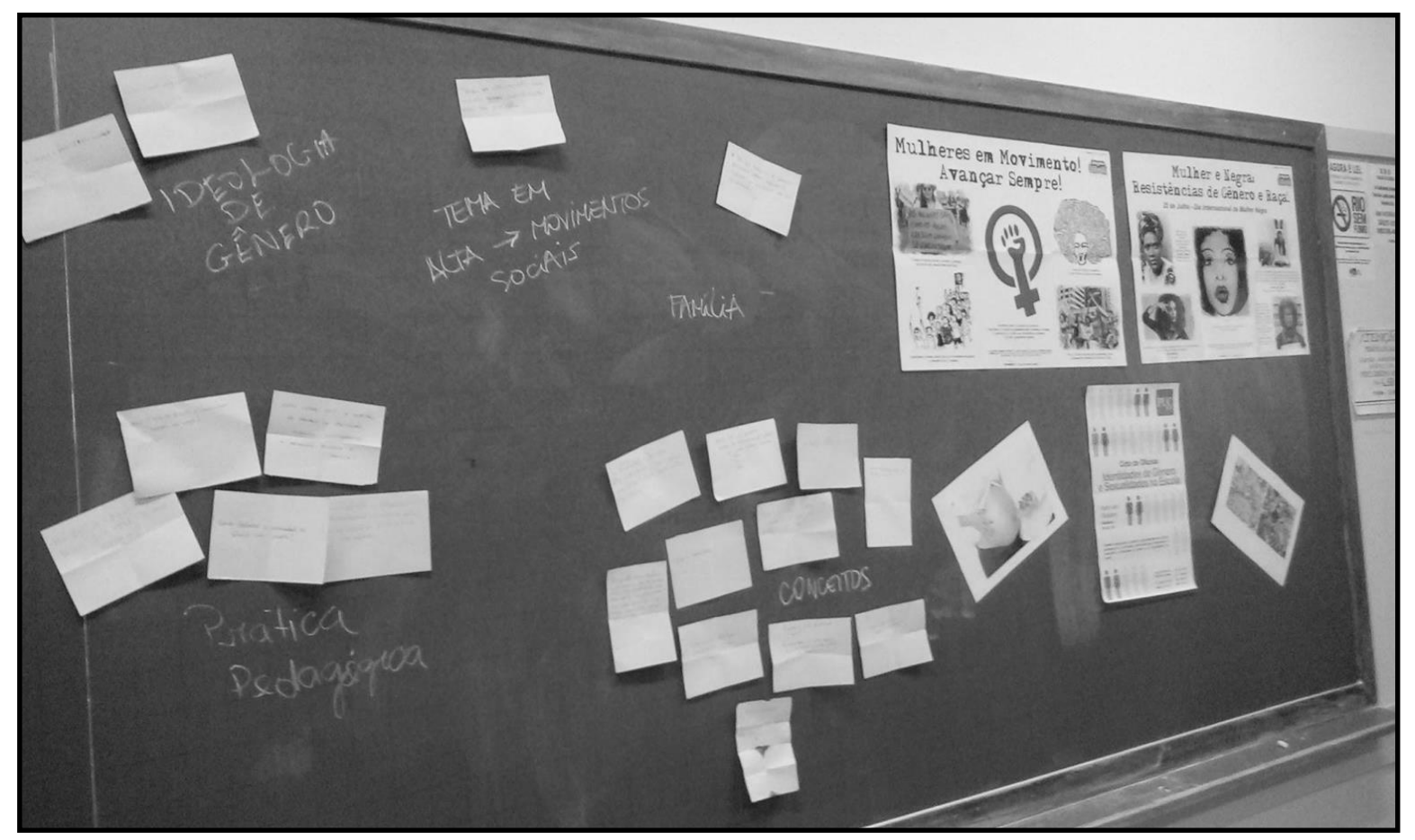

Figura 1: Painel temático formado com as perguntas

A caixa de perguntas consiste numa atividade em que cada estudante presente na sala deve escrever uma pergunta sobre determinado tema em um pedaço de papel. O papel não precisa estar identificado. Ele deve ser dobrado e posto em uma caixa. Após colocarem todos os papéis na caixa, a mediadora retira um a um para leitura e explicação, que pode gerar um debate coletivo. Esta atividade propicia diálogos sobre assuntos muitas vezes não explorados, uma vez que a caixa garante o anonimato de quem escreveu a pergunta. Ela traz concepções presentes no imaginário social e coletivo sobre o tema proposto, captadas pelos indivíduos. Ao explorar essas visões do cotidiano, a atividade trabalha na tensão entre saberes oriundos do senso comum e saberes acadêmicos, aproximando teoria e prática na sala de aula.

[...] senso comum é um conjunto de opiniões e valores característicos daquilo que é correntemente aceito em um meio social determinando. 
O senso comum consiste em uma série de crenças admitidas no seio de uma sociedade determinada e que seus membros presumem serem partilhadas por todo ser racional. (Hilton JAPIASSÚ, 2006, p. 250)

Por senso comum entendemos os saberes que circundam o imaginário social e cultural, saberes produzidos pela experiência e reproduzidos no cotidiano sem que reflexões sejam realizadas sobre o significado dessas (re)produções. Assim, o exercício da oficina traz à tona esses saberes e os torna passíveis de problematização. Ou seja, expõe percepções estereotipadas e, muitas vezes, preconceituosas e abre a possibilidade de reorganizar as compreensões das identidades de gênero e das sexualidades. Nosso intuito com essa prática é propiciar na turma a reflexão sobre as construções presentes no imaginário social, pautando as noções de diálogo e tolerância, como valores que norteiam o processo de ensino aprendizagem.

Educar para a tolerância é um processo fundamental, se é que queremos construir e manter uma sociedade plural. Educar para a tolerância é mais necessário e produtivo do que se imagina inicialmente, pois busca intervir em valores e atitudes moralmente exigíveis. Educar para a tolerância é uma questão de justiça que visa assegurar a multiplicidade possível de ofertas de vida feliz e condizentes com a estatura moral que os tempos atuais nos exigem. (Marcelo ANDRADE, 2009, p. 207)

As perguntas das três caixas dividimos em nove eixos temáticos: $(i)$ a prática pedagógica e o momento de abordagem dos temas; (ii) conceituação das categorias gênero e sexualidade; (iii) relações entre as categorias e a família; (iv) identidade e movimentos sociais; $(v)$ relações entre as categorias e as religiões; (vi) tabus; (vii) preconceitos e discriminações; (viii) desigualdades de gênero; e (ix) estereótipos. A Tabela 1 expressa a relação entre cada eixo temático com a quantidade, nas três oficinas, de perguntas realizadas.

Tabela 1: Quantidade de perguntas por eixos temáticos

\begin{tabular}{c|c}
\hline Eixo Temático & Quantidad \\
\hline Prática Pedagógica & 28 \\
\hline Conceitos & 22 \\
\hline Família e Escola & 7 \\
\hline Identidades de Gênero e LGBT & 7 \\
\hline Religião e Escola & 5 \\
\hline Temas Tabus & 4 \\
\hline
\end{tabular}




\begin{tabular}{|c|c|}
\hline Preconceitos e Discriminações & 3 \\
\hline Desigualdades de Gênero & 2 \\
\hline Estereótipos & 2 \\
\hline Total & 80 \\
\hline
\end{tabular}

$\mathrm{O}$ maior eixo de perguntas diz respeito à $(i)$ prática pedagógica. Nele, consideramos todas as questões que tratavam da escola, que problematizam o espaço e as resistências encontradas na inserção das temáticas de gênero e sexualidade, sobre como fazer e em que momento. O como ensinar é uma dúvida recorrente, o que tem relação com a própria condição de graduandas.

A questão do como ensinar, vinha constantemente acompanhada do como lidar, como fazer. Falar na diversidade de gênero e sexualidades gera uma angústia nas alunas. Essas estudantes declararam que passaram por sua trajetória escolar sem essas discussões. No entanto, não podemos afirmar que em suas trajetórias escolares e na formação docente não ocorram ensinamentos de gênero e sexualidades.

(...) o que deve nos interessar é o fato de que eles estão nos dizendo coisas, de que eles são integrantes da sociedade em vivemos e, além disso, o fato de que, de uma forma ou de outra, eles estão em nossas escolas. Não podemos deixar de lhes prestar atenção. (Guacira Lopes LOURO, 2003, p. 52)

Esses sujeitos que estão na escola e que a autora diz que devemos prestar atenção são os sujeitos que excedem aos padrões de gênero e sexualidades, são esses que geram angústia nas alunas da graduação, pois elas não sabem como lidar com essas diferenças, nem como ensinar sobre essas diferenças. Isso aponta para a necessidade de inserção de debates em torno da diversidade de gênero e das sexualidades no currículo das formações docentes.

Percebemos nas três turmas que houve também uma quantidade grande de questões destinadas aos (ii) conceitos de gênero e sexualidade. Em todas as oficinas, a pergunta $O$ que é gênero? apareceu tanto na caixa, quanto verbalmente. Essa pergunta, da mesma forma que o a angústia, diz sobre uma lacuna presente na formação escolar. As estudantes não sabem ou ao menos não demonstram clareza suficiente sobre o que é gênero e o que é sexualidade. Quando tentam explicar com suas próprias palavras, os conceitos são apresentados misturados. 
Sobre isso, entendemos que as identidades de gênero e sexualidades caminham juntas e preenchem diversas esferas da vida dos sujeitos, porém, o que ressaltamos aqui é a dificuldade de categorização. Por exemplo, percebemos a dificuldade das alunas para entender que entre homossexualidade e variação de gênero existe relação, não causalidade. Na maioria dos casos, as definições estão ligadas a percepções estritamente biológicas e numa variação binária entre feminino e masculino. Uma fala bastante recorrente é a percepção da homossexualidade masculina como uma perda da possibilidade do gênero masculino para o indivíduo gay, como se falar em masculinidade fosse algo dependente da heterossexualidade. Ou seja, as percepções se ancoram na heteronormatividade.

Leandro Colling (2010, p. 41) afirma que a heteronormatividade é uma forma de explicar a relação entre gênero e sexo de forma linear, ou seja, "as pessoas com genitália masculina devem se comportar como machos, másculos, e as com genitália feminina devem ser femininas e delicadas". Assim, quando no decorrer da oficina nos depararmos com esses discursos, tentamos expor que essa é uma ideia difundida em nossa sociedade e que ela está fundamentada em percepções restritivas e que condicionam os sujeitos a determinados papéis sociais fixos. Dessa forma, a mediação buscou problematizar que existem inúmeras possibilidades de ser cada uma dessas categorias e que elas independem da sexualidade de cada indivíduo. 'Nada há de puramente 'natural' e 'dado' em tudo isso: ser homem e ser mulher constituem-se em processos que acontecem no âmbito da cultura" (Guacira Lopes LOURO, 2008, p. 18).

Encontramos muitas dúvidas e uma demanda grande por mais informações. $\mathrm{Ou}$ seja, mesmo as estudantes apresentando definições de gênero e sexualidade marcadas pelo viés biológico, não observamos resistências para debater o tema. Pelo contrário, as questões Como surgiram os conceitos de gênero e sexualidade?, Qual a diferença de gênero e sexualidade?, Qual a diferença entre o gênero e o sexo? e $O$ gênero é uma construção social? demonstram o interesse por parte das estudantes em compreender essas categorias em sua complexidade conceitual e histórica.

Ainda em função dos conceitos, questões como A sexualidade é uma opção ou é pré-determinada antes de nascer? expõem as dúvidas sobre a origem da sexualidade ao longo da vida dos sujeitos, ou seja, se é algo que surge num dado momento na vida do sujeito ou se é involuntário aos indivíduos. A palavra opção traz com maior força a ideia de escolha individual, como se a sexualidade se transformasse de um dia para o outro de 
acordo com os interesses únicos de quem a experimenta. Ao mesmo tempo, quando se questiona se é pré-determinada antes do nascimento do sujeito, traz consigo a ideia de que a sexualidade é algo originário da própria vida daquele indivíduo, da essência do indivíduo, o que anula qualquer possibilidade de mudança, consciente ou não. Numa outra pergunta, Quais são as causas da orientação sexual? Biológicas? Sociais?, a noção de causa retoma a questão acima, de que algo rompe a naturalidade da sexualidade.

Essas questões sobre a origem da sexualidade no indivíduo apontam para uma compreensão do sexo como algo normativo. Ou seja, é ser um conjunto de saberes e práticas que cercam a sexualidade humana, como afirma Michel Foucault (2013).

O corpo é o lugar de materialização desses discursos. Primeiro porque as diferenças entre os gêneros, entre ser homem e mulher, entre ser heterossexual e homossexual, são diferenças que se invocam quase sempre como uma questão de diferença material, algo que se identifica, que se lê nos corpos. No entanto, essas diferenças em torno das homossexualidades não podem ser entendidas simplesmente $\mathrm{e}$ isoladamente como diferenças materiais, mas em relação, são marcadas e formadas pelas formas que são construídas e entendidas discursivamente, dizem respeito a práticas discursivas. (Anderson FERRARI, 2011, p. 105)

Assim, a normatividade implícita nas perguntas revela o quanto o imaginário cotidiano ainda entende as sexualidades e os gêneros como categorias essencializadas, demarcando a diferença como uma ruptura desse ideal heteronormativo.

No eixo temático sobre (iii) família, as perguntas que diziam das relações entre a educação e a experiência familiar envolvem tanto dúvidas sobre como lidar com famílias mais resistentes ao trabalho de gênero sexualidade na escola, quanto questões sobre como agir na mediação entre crianças pertencentes a famílias homossexuais com a escola. Também foram feitas perguntas sobre como abordar o tema família na educação, sem ser reduzido à forma tradicional e nuclear (mãe, pai e filhas), por exemplo: Como trabalhar questões de gênero e sexualidade se eu tiver uma turma cujos pais não sejam a favor? e Como lidar com a questão de gênero na educação infantil, considerando a relação escola e família?.

A educação infantil aparecia de forma recorrente em todas as turmas que realizamos as oficinas - quase sempre como uma dúvida ou como um desafio para a abordagem de gênero e sexualidade, como se ensinar para crianças menores fosse muito mais complexo. Acreditamos que essa atmosfera de complexidade se dê em virtude de se 
pensar as atividades de orientação sexual realizadas com adolescentes e jovens, perdendo de vista que as atividades para a faixa infantil tem outro caráter, outras propostas. Assim, nesses momentos, explicamos que em cada faixa etária a abordagem se adequa, de tal forma que na educação infantil podemos problematizar o que significa dizer que determinada cor é de menina ou menino; por que separamos as crianças pelo gênero na hora de organizar filas e brincadeiras e se existem outras possibilidades de fazer essa organização; qual a relevância de se discutir a própria noção de família, na medida em que podemos apresentar diversidades de modelos familiares, tais como composições de mães e filhas, avós e netas, famílias com duas mães ou dois pais, entre outras.

No eixo sobre $(i v)$ identidades de gênero e LGBT agrupamos todas as questões que faziam referência à presença da diversidade sexual e de gênero nas escolas, exemplos: Como uma criança que não se identifica com o seu gênero é incluída na escola? ou Como a escola deve tratá-la, se outras crianças a tratam de forma diferente?. Aqui, percebemos uma preocupação com a inclusão das crianças transgênero ${ }^{8}$ e com possíveis situações de preconceito que elas podem sofrer no ambiente escolar.

Esse eixo se aproxima do eixo sobre $(v)$ religião, pois as perguntas deste eram direcionadas novamente ao como lidar diante de posturas conservadoras. As alunas relacionam a questão religiosa a posturas preconceituosas e discriminatórias, como apontou a Turma B: Por que muitas religiões são contra as relações homossexuais? Como confrontar as questões de gênero e transgênero com os discursos religiosos que algumas crianças trazem (na escola)? Exemplo: "Deus criou homem e mulher", "Ideologia de gênero", "Se criou homem, é homem".

Ainda no eixo da religião, foram feitas questões específicas sobre a ideologia de gênero: $O$ que é ideologia de gênero? Qual é a relação com este tema? e $O$ que propõe uma ideologia de gênero?. Apesar do termo ter cada vez mais visibilidade, as estudantes não sabem o que ele significa. Tema recente e externo ao campo de estudos de gênero e à própria educação, Jimena Furlani (2016, p. 2) explica que “a ideologia de gênero é um termo que apareceu nas discussões sobre os Planos de Educação, nos últimos dois anos, e tem sido apresentado a nós como algo muito ruim, que visa destruir as famílias".

\footnotetext{
${ }^{8}$ As palavras transgênero e transexual são utilizadas para pessoas que não se enquadram no gênero determinado a elas no nascimento, ou antes, dele, uma vez que durante a gestação já existe expectativa em torno da criança quanto ao seu gênero. Os gêneros não-binários, além de transgredirem à essa expectativa, ultrapassam os limites dos polos e se fixam ou fluem em diversos pontos do espectro de gênero (Neilton DOS REIS; Raquel PINHO, 2016). 
A autora vem se aprofundando no estudo do termo e aponta que inicialmente a reação das teóricas era de negar sua existência. Porém, conforme fora adquirindo mais espaço, foi importante que os estudos de gênero e sexualidades fizessem uma revisão do termo e assumissem que o trabalho de pesquisa do campo não dialoga com essa proposta. Ao contrário, os estudos de gênero e sexualidade realizam uma problematização das desigualdades e assimetrias presentes nas relações entre os diferentes gêneros e lutam por valores pautados na igualdade de direitos e respeito à diferença.

Considerarmos que o conceito gênero permite as discussões acerca da posição da mulher na sociedade, da aceitação dos novos arranjos familiares, das novas conjugalidades nos relacionamentos afetivos, ampliação da forma de ver os sujeitos da pós-modernidade e no reconhecimento da chamada diversidade sexual e de gênero, então, não há campo do conhecimento contemporâneo mais impactante e perturbador para as instituições conservadoras e tradicionais que os efeitos reflexivos dos estudos de gênero. Isso nos faz entender porque o empenho tão enfático, persistente e até, em algumas situações, antiético das instituições que criaram e divulgaram essa narrativa denominada "ideologia de gênero". Na minha opinião, há usos distintos da chamada "ideologia de gênero". Parece que, no âmbito da cúpula da Igreja Católica, trata-se de uma questão dogmática e relacionada aos valores da ideologia judaico-cristã, que, segundo seus representantes, estariam sendo ameaçados pelo conceito gênero por causa das mudanças no comportamento das mulheres e nas leis sobre aborto, por exemplo, da aceitação das várias famílias e do reconhecimento dos direitos da população LGBT. Outro uso vem de representantes evangélicos: embora existam aqueles católicos que se aproveitam eleitoralmente dessa narrativa, usar a "ideologia de gênero" e sua suposta "ameaça" às crianças e à família tem sido mais presente em candidatos evangélicos - vide a chamada bancada cristã, que não apenas no Congresso Nacional, mas em todos os legislativos do país, deve aumentar, nas próximas eleições, à custa de campanhas cujo foco de "convencimento" deverá ser combater a ideologia de gênero. (Jimena FURLANI, 2016, p. 3)

Nos (vi) temas tabus, as perguntas foram sobre violência, assédio e aborto. Sobre violências e assédios, abordamos que enquanto pessoas que integram uma sociedade baseada em valores machistas e de herança patriarcal, estamos sujeitas a essas situações, mas que na medida que ampliamos as possibilidades de discussão das diferenças de gênero e da valorização e empoderamento das identidades femininas e LGBT, estamos favorecendo a reflexão e a problematização do assédio como algo comum. Sobre o aborto, esses mesmos valores, juntamente com questões religiosas arraigadas em nossa sociedade, também dificultam o avanço dos debates. 
No eixo sobre (vii) preconceitos, as perguntas estavam relacionadas a dois pontos principais: $(a)$ por que tanta rejeição à entrada da temática de gênero e sexualidade na escola; (b) como agir diante de situações de preconceitos. Sobre a rejeição, eles perguntaram Como você acha que pode ser introduzida a questão de gênero nas escolas? e Por que [você] acredita ter tanto preconceito em relação a isso?. Nesse caso, buscamos expor que falar sobre gêneros e sexualidades é falar sobre as identidades que muitas vezes são colocadas em posição de marginalizadas e, por isso, são negadas. Os estudos de gênero e sexualidades possibilitam retirar essas identidades da invisibilização e do silenciamento e colocá-las em debate, problematizando tanto a norma, quanto a noção de desvios.

\begin{abstract}
A escola na forma como se apresenta hoje pouco ou não questiona o lugar em que as identidades heterossexuais estão colocadas. Ao contrário, a heterossexualidade é exposta, reiterada e compreendida como um grupo unificado e homogêneo, enquanto as identidades homossexuais são identificadas como um problema com o qual a escola precisa lidar, se possível de forma discreta, com as famílias em particular, quando a necessidade surge. (BASTOS, Felipe; PINHO, Raquel; PULCINO, Rachel; 2015, p. 68)
\end{abstract}

A resistência à entrada da temática na escola é parte e produto do esforço de conservação das estruturas sociais e da manutenção do status quo. Quando o debate acontece, vem para apagar incêndios, ou seja, quando uma situação de preconceito ocorre e a escola precisa agir diante da situação. Sendo assim, durante a oficina, explicamos que pensar uma educação para a diversidade é se preocupar com a situação de preconceito, mas é principalmente trabalhar ao longo de todo o ano, inserindo o tema nas práticas pedagógicas, ancoradas em valores como a tolerância, o respeito e o diálogo entre diferentes culturas.

Ao abordarem o tema da (viii) desigualdade, as perguntas giraram em torno da divisão social do trabalho, questionando como certos privilégios masculinos são mantidos a despeito das mudanças sociais sobre equidade dos gêneros. Também foram feitas perguntas sobre as conquistas e os impasses presentes no mercado de trabalho para as mulheres e como estas são influenciadas pela questão da maternidade. Pensamos que essas questões, como são numericamente muito menores sejam influenciadas pela experiência individual das estudantes, por exemplo, na Turma B, havia uma aluna grávida e uma aluna que já era mãe. Elas se posicionaram bastante nesse momento, colocando o quão difícil é equilibrar diversas funções e tarefas. 
A falta de creches e de políticas adequadas para a conciliação entre a rotina de trabalho e o cuidado com os filhos pequenos penaliza as mulheres, muito mais do que os homens, em sociedades nas quais a divisão dos papéis permanece atada a compreensões convencionais do feminino e do masculino. (Flávia BIROLI; Luis Felipe MIGUEL, 2014, p. 11)

O tema das desigualdades de gênero diz sobre os modos como nossa sociedade organiza as funções de trabalho, para além do próprio mercado de trabalho, abrindo possibilidades para pensarmos também a vida doméstica. O debate na Turma B se desenvolveu a partir do questionamento do porquê ainda hoje as políticas para crianças estão atreladas às políticas para mulheres. Como Flávia Biroli e Luis Felipe Miguel (2014) apontam, nossa sociedade ainda é marcada por uma divisão social do trabalho, e parte da tarefa de possibilitar mudanças está na entrada da temática de gênero no cotidiano escolar. Ou seja, ensinar que todas as crianças devem cuidar dos seus objetos e da limpeza, possibilitar que meninos exercem funções em brincadeiras de bonecas, são formas de ensinar a vivenciar o cuidado com o outro e inserir as crianças numa lógica de divisão do trabalho mais igualitária para os gêneros.

No tema dos (ix) estereótipos, as questões tratavam sobre a possibilidade de se ensinar sem recorrer aos estereótipos, sobre por que as cores rosa e azul são utilizadas como formas de separar o que é do universo feminino e masculino. Entendemos que faz parte da compreensão humana construir categorias e modelos de análise, é uma forma de organizar as coisas, porém, as categorizações se tornam limitadoras e restringem a liberdade dos sujeitos devido ao seu caráter normativo. É importante manter em perspectiva esta tensão entre categoria e norma presente na prática pedagógica.

A partir dos temas emergentes na prática, observamos o quanto a caixa de perguntas auxilia na elaboração do currículo e na problematização de conceitos e valores presentes em nossa sociedade, propiciando momentos de reflexão e (des)construção.

\section{Considerações Finais}

Identificamos como lacunar o espaço ocupado pela temática de gênero e sexualidade na formação docente. Tal lacuna na formação inicial se desdobra em ausências na Educação Básica, o que pode contribuir para a reprodução de um status quo de preconceito e desrespeito no espaço escolar. 
Realizamos as oficinas em universidades reconhecidas por sua qualidade no ensino. Mesmo nelas, não há tradição de oferecer disciplinas específicas destinadas ao debate de gênero e sexualidade; quando elas ocorreram, é em caráter eletivo. Com efeito, percebemos que a inserção dessa temática ocorre em função da iniciativa de professoras que consideram relevante debater esses temas.

Assim, como bem mostraram as oficinas, a entrada dos estudos de gênero e sexualidades na formação docente ocorre pelas beiradas, apesar das próprias estudantes demandarem espaços e momentos para a discussão dessas questões. Como ocorre na educação escolar, observamos um ensino superior no qual não há muita escuta das suas alunas, das suas demandas, dos seus interesses e, com isso, adia questões ligadas à diversidade e à diferença no currículo oficial e na vivência universitária.

Nossa percepção dialoga com a visão de Helena Altamnn (2013) sobre o lugar ocupado pela diversidade sexual na formação docente. A autora afirma que apesar da ampliação dos estudos de gênero e sexualidades no ambiente acadêmico e do aumento dos debates realizados em escolas, o currículo da formação docente ainda se revela tradicional.

O caráter pungente desta temática a torna extremamente mobilizadora de eventos, cursos de formação continuada e de especialização, pesquisas de pós-graduação etc. Essas possibilidades educativas têm sido exploradas. Entre outras, há potencialidade exatamente no trabalho a partir de uma experiência já construída no campo profissional, que pode ser ressignificada e reelaborada através de nova formação. (Helena ALTMANN, 2013, p. 79)

Em nossas experiências, encontramos futuras professoras da educação básica interessadas em compreender mais sobre os conceitos de gênero e sexualidades, curiosas e pensando em como agir diante de situações de conflitos com a equipe escolar, entre estudantes ou com a família. Suas preocupações em como agir, como ensinar demonstram por suas intenções em conduzir este debate na escola e registram um apelo ao campo da didática.

Além de curiosidade, identificamos muito desconhecimento. Questões como: $O$ que é gênero?, Quais são as causas da orientação sexual?, O que é ideologia de gênero?, Como lidar com a questão de gênero na educação infantil, considerando a relação escola e família?, evidenciam que ainda temos um longo caminho para percorrer na formação 
docente para o trabalho com a diversidade de gênero e sexualidades, tanto na própria formação, quanto no chão da escola.

Elas, as perguntas, expõem o quanto esses temas foram e ainda são silenciados ao longo da trajetória dessas estudantes. Essa ausência é uma forma de silenciar também sujeitos e práticas que vivenciam nessas categorias. A falta de visibilidade demarca o seu não lugar.

$\mathrm{O}$ silêncio traz à tona uma vulnerabilidade anterior em relação à linguagem que temos em função de sermos seres dependemos da nomeação do Outro para existir. O silêncio é a negação do reconhecimento e ambos formam parte de um ritual mais amplo de interpelação dos sujeitos e construção das subjetividades como algo que estamos constantemente sujeitos ou assujeitados. (Anderson FERRARI, 2011, p. 101)

A carência de discussão desses temas gera desconhecimentos, reprodução de estereótipos e até angústia em algumas alunas. Por isso, para quebrar este ciclo de silenciamentos e ausências, apostamos em trazer essas identidades - e junto com elas seus temas, suas emoções e seus corpos - para o debate na formação docente e, consequentemente, para o espaço escolar.

\section{Referências}

ALTMANN, Helena. Diversidade sexual e educação: desafios para a formação docente. Sexualidad, Salud y Sociedad - Revista Latinoamericana, Rio de Janeiro: UERJ, n.13, Abr. 2013, pp.69-82.

ANDRADE, Marcelo; SACAVINO, Susana. Oficinas Pedagógicas em Direitos Humanos: uma aposta na formação de política com grupos populares. IN: CANDAU, Vera; SACAVINO, Susana: Educar em Tempos difíceis: construindo caminhos. Rio de Janeiro: 7Letras, 2011.

; LUCINDA, Maria da Consolação. Oficinas pedagógicas e direitos humanos: uma aposta na formação política com grupos populares. In: CANDAU, Vera Maria e SACAVINO, Suzana (orgs). Educar em tempos difíceis: construindo caminhos. Rio de Janeiro: 7Letras, 2011.

Tolerar é pouco? Pluralismo, mínimos éticos e prática pedagógica. Petrópolis: RJ: DP et Alli: De Petrus; Rio de Janeiro: Novamerica, 2009.

BASTOS, Felipe; PINHO, Raquel; PULCINO, Rachel. Diversidade sexual na escola: três perspectivas sobre silenciamentos de sujeitos e saberes. IN: ANDRADE, Marcelo. Diferenças silenciadas: pesquisas em educação, preconceitos e discriminações. Rio de Janeiro: 7Letras, 2015. 
BIROLI, Flávia; MIGUEL, Luis Felipe. Introdução. IN: MIGUEL, Luis Felipe; BIROLI, Flávia. Feminismo e Política: uma introdução. São Paulo: Boitempo, 2014.

BRASIL. Secretaria de Educação Fundamental. Parâmetros Curriculares Nacionais: terceiro e quarto ciclos. Orientação Sexual. Brasília: MEC/SEF, 1998.

COLLING, Leandro. O que perdemos com os preconceitos? São Paulo: Revista Cult. Edição Especial n. 6, p. 38-41, janeiro de 2016.

FORQUIN, Jean-Claude. Escola e Cultura. Porto Alegre: Artes Médicas, 1993.

FERRARI, Anderson. Silêncio e silenciamento. IN: FERRARI, Anderson; MARQUES, Luciana Pacheco. Silêncios e Educação. Juiz de Fora: Ed. UFJF, 2011.

FOUCAULT, Michel. História da Sexualidade I: A vontade de saber. Rio de Janeiro: Edições Graal, 2013.

FURLANI, Jimena. Mitos e Tabus da sexualidade humana: subsídios ao trabalho em educação sexual. Belo Horizonte: Autêntica, 2009.

. Existe "ideologia de gênero"? Pública, 30 de agosto de 2016. Entrevistadora: Andrea Dip. Disponível em: <http://apublica.org/2016/08/existeideologia-de-genero/>. Acesso em: 6 de novembro de 2016.

LOPES, Alice Casimiro. Conhecimento escolar: ciência e cotidiano. Rio de Janeiro: EdUERJ, 1999.

LOURO, Guacira Lopes. Gênero e sexualidade: pedagogias contemporâneas. PróPosições. Campinas, v. 19, n. 2, maio/ago., 2008.

"excêntrico". IN:

Currículo, gênero e sexualidade - O "normal", o "diferente" e o gênero e sexualidade: um debate contemporâneo na educação. Petrópolis, RJ: Vozes, 2003.

MORAES, Carla de; FERREIRA, Michelle; FERRAZ, Fernando; AYRES, Ana Cléa; DORVILLÉ, Luís. Educação sexual no Ensino Fundamental: concepções prévias e dúvidas de alunos. Anais do I Encontro Nacional de Ensino de Biologia e do III Encontro Regional de Ensino de Biologia RJ/ES. Ensino de Biologia: conhecimentos e valores em disputa. Rio de Janeiro: UFRJ, 2005.

SCOTT, Joan. "Gênero: uma categoria útil de análise histórica". Educação \& Realidade, Porto Alegre, v. 20, n. 2, p. 71-99, 1995.

VENÂNCIO, Letícia Maria; PINHEIRO, Mary Cristina; ACOSTA, Priscila. Trabalhando o tema sexualidade na escola: o uso da técnica caixa de perguntas anônimas. Anais do II Congresso de Educação da Grande Dourados. Dourados: UFGD, 2016. 
APÊNDICE 1 - Roteiro da oficina "Corpo, gênero e sexualidade na escola"

\section{Material}

1 caixa colorida; 30 tiras de papel colorido; Fita crepe; 30 cópias dos conceitos; Computador; Data show; Caixa de som.

\section{Sensibilização (40 min)}

Atividade: Caixa de perguntas

Após uma breve apresentação, as mediadoras colocam uma colagem de imagens no quadro -imagens que ajudem as alunas a pensar este tema. Elas distribuem uma tira de papel para cada aluna e pedem que escrevam uma pergunta sobre o tema, sem se identificar. Depois de escrever a pergunta, o papel é dobrado e colocado na caixa. Depois que todas terminaram, as mediadoras tiram uma tira de papel de cada vez, leem a pergunta e colam no quadro. As perguntas devem ser agrupadas por assunto. Depois de tudo colado, as mediadoras podem perguntar se alguém sabe responder a dúvida da colega. Elas explicam brevemente as questões levantadas.

\section{Aprofundamento (40 min)}

Atividade: Discussão de conceitos

A turma é dividida em 6 grupos. Cada uma recebe uma cópia de conceitos de gênero e de sexualidade. O grupo lê o texto e debate. Em seguida, os grupos se juntam numa grande roda e explicam o que debateram para toda a turma.

\section{Compromisso (20 min)}

Atividade: Refletir sobre as identidades

Exibição do vídeo "Não é pra sair", com Nátaly Neri e Jout jout. Devido ao tempo, a turma será orientada a assistir e refletir sobre o tema, mas não teremos discussão. 